\title{
SOBERANÍA, GLOBALIZACIÓN Y LA CONSTITUCIÓN DE SIGNIFICADO
}

Farid Samir Benavides Vanegas*

Resumen: En este ensayo pretendo demostrar cómo la pérdida de soberanía del Derecho y de la nación ha implicado la emergencia de nuevos lugares de construcción de la identidad y cómo estas nuevas identidades han llegado a ser globales, debido a la pérdida de centralidad del Estado-Nación como lugar de producción de significado. Mediante el análisis del concepto de soberanía y de su relación con el poder de nombrar que posee el Estado, ejercido a través de la ley, quiero mostrar cómo en una sociedad del espectáculo este poder es quitado al Estado y dado a otros lugares que puedan garantizar la pasividad de los espectadores y, por tanto, la ausencia de resistencia en la construcción del significado. Esto lo haré mediante el análisis de una telenovela colombiana y su manejo del concepto de corrupción para mostrar de qué manera el significado legal fue superado por aquel construido en los medios de comunicación. Palabras clave. Globalización; Construcción de identidades; Teoría constitutiva del Derecho; Medios de comunicación.

PhD en Ciencia Política de la University of Massachusetts at Amherst, PhD en Derecho de la Universitat Pompeu Fabra, PhD en Filosofía de la Universidad de Barcelona. Profesor Asociado, Director Área de Derecho Penal, Procesal Penal y Criminología de la Universidad de los Andes. Correo-e: fs.benavides@uniandes.edu.co.Bogotá,Colombia.Fecha de recepción: 20 de marzo de 2014. Fecha de modificación: 16 de mayo de 2014. Fecha de aprobación: 30 de julio de 2015. Para citar el artículo: FARID SAMIR BENAVIDES VANEGAS (2015). "Soberanía, globalización y la constitución de significado", Revista Derecho Penal y Criminología, Vol. 36, n. ${ }^{\circ}$ 100, enero-junio de 2015. Bogotá: Universidad Externado de Colombia, pp. 45-61. DOI: http://dx.doi.org/10.18601/ 01210483.v36n100.03 


\title{
SOVEREIGNTY, GLOBALIZATION AND THE CONSTITUTION OF MEANING
}

\begin{abstract}
In this essay I wish to show how law's and the nation's loss of sovereignty have meant the emergence of new sites of identity construction and how these new identities have become global due to the loss of centrality of the nation state as a place of meaning production. By analyzing the concept of sovereignty and its relation to the power of naming held by the State, and exercised through the law, I want to show how in a society of the spectacle that power is removed from the State and given to other places that can ensure passivity of viewers and thus the absence of resistance in the construction of meaning. This I will do by analyzing a Colombian soap opera and its handling of the concept of corruption to show legal meaning was overtaken by the one built in the media.

Keywords. Globalization; Constitution of Identities; Legal Constitutive Theory; Social Media.
\end{abstract}

\section{INTRODUCCIÓN}

En los últimos años, hemos oído hablar con mucha insistencia acerca de la globalización de la economía, de cómo Colombia debe responder a las exigencias de la globalización, etc. El debate que se desarrolla en Colombia acerca de este tópico parece estar más centrado en la globalización económica, sin que se mencione la influencia en otros campos, como el jurídico, por ejemplo. Salvo algunos escritos que se han ocupado del tema (BERGALLI, 2000 y s.f.), es poco lo que se ha discutido en Colombia acerca de la cuestión de la globalización y del Derecho. Sin embargo, en estos escritos no se tiene en cuenta la dimensión constitutiva del Derecho y cómo el fenómeno conocido como globalización ha significado la perdida de centralidad del Estado-nación en la constitución de las identidades de los sujetos ${ }^{1}$.

En este ensayo pretendo demostrar cómo la pérdida de soberanía del Derecho y de la Nación ha implicado la emergencia de nuevos lugares de construcción de la identidad y como estas nuevas identidades han llegado a ser globales, debido a la pérdida de centralidad del Estado-Nación como lugar de producción de significado. Mediante el análisis del concepto de soberanía y de su relación con el poder de nombrar que posee el Estado, ejercido a través de la ley, quiero mostrar cómo en una sociedad del espectáculo este poder es quitado al Estado y dado a otros lugares de puedan garantizar la pasividad de los espectadores y, por tanto, la ausencia de resistencia en la construcción del significado. Esto lo haré mediante el análisis de una telenovela colombiana y su manejo del concepto de corrupción, para mostrar de qué manera

1 Brigham (1996) y Hunt (1993). 
el significado legal fue superado por aquel construido en los medios de comunicación. Este tipo de análisis servirá en el futuro para discutir el papel de las instancias informales en la construcción de significado jurídico, mostrando cómo la esperanza positivista de una ley monosignificante no puede ser sostenida más en la sociedad actual. La fragmentación de la sociedad postindustrial afecta también a los productos simbólicos y a demostrar ello apunta este trabajo.

\section{QUÉ ES LA GLOBALIZACIÓN}

Hoy en día, existe consenso respecto al hecho de que vivimos en una época de globalización. Sin embargo, no existe consenso con respecto al referente material de este término ni acerca de la actitud política frente al fenómeno. Para quienes la globalización es una necesidad, no hay más remedio que someterse a sus designios, en tanto que para quienes opinan que la globalización es la imposición de modelos culturales y económicos centrales, la única salida es la resistencia.

De acuerdo con el filósofo católico italiano GiAnNi V ATTIMO, la nuestra es una sociedad transparente en la cual los medios de comunicación permiten que todas nuestras producciones culturales sean conocidas alrededor del mundo. En contra de aquellos que creen que la globalización de los medios de comunicación traerá una peligrosa homogenización de la sociedad, VATTIMO (1991) responde que la sociedad global tendrá un grupo diverso de localidades, esto es, la arena global permitirá que los diferentes significados globales se pongan en diálogo uno con otro.

VATTIMO comparte la concepción de ROBERTSOn acerca de lo local como parte de lo global y, por tanto, la imposibilidad de conflictos entre las globalidades y las localidades. Basado en este análisis, ROBERTSON creó el término glocalización para reemplazar el neologismo globalización, pues considera que aquel refleja mejor el proceso que el mundo ha vivido en las últimas tres décadas. Esta idea de glocalización concibe al mundo como teniendo un proceso positivo en el cual los productos locales -incluso la producción de significado-son dispuestos en la arena global. Esto se refleja en el hecho de que uno puede comer comida mexicana o tai en cualquier ciudad de los Estados Unidos o que cualquier mexicano o tailandés pueda comer una hamburguesa de McDonalds en cualquier lugar del mundo (BECK, 1998). Los análisis de VATTIMO y de RoBERTSON no dan cuenta de la imposición de valores y significados occidentales en diversas regiones y tampoco de la visión distorsionada que de estas localidades se tiene en los países centrales ${ }^{2}$.

En contra de esta visión optimista de la globalización, existe un grupo importante de autores que muestran la variedad de significados de la globalización, resaltando el

2 Said (1977), Mudimbe (1988), Lao Montes (2001). 
hecho de que no todos ellos son positivos. ULRICH BECK, por ejemplo, nos recuerda que el proceso que conocemos como globalización no es más que la extensión a escala mundial de la economía neoliberal, es decir, que aquello que entendemos como globalización es solo el proceso por el cual la economía se libera de las restricciones nacionales para garantizar la libre circulación de capitales. BECK distingue entre globalismo, para referirse a la ideología neoliberal de acuerdo con la cual el mundo es un mercado global, y globalidad, que hace referencia a una sociedad global, esto es, una sociedad que se percibe y refleja como global. Mientras el primero implica homogeneidad, el segundo implica pluralidad y falta de integración. De acuerdo con este análisis, este proceso está destruyendo al Estado de Bienestar y a la democracia, por lo que concluye con un llamado a la defensa de la justicia social, pese a la globalización, si es del caso (BECK, Op. cit.).

Pese a que el análisis de BECK supera el optimismo de VATTIMO, es preciso señalar que su perspectiva sigue siendo eurocentrista, olvidando que la justicia social en los países del centro con frecuencia ha estado basada en la explotación y el sometimiento de los países periféricos. Además, su perspectiva se ubica en la cuestión meramente económica, dejando de lado lo relativo a la producción de significado.

La globalización cultural y particularmente la globalización del Derecho ha sido objeto de análisis por parte de ROBERTO BERGALli y de BOAVENTURA DE SOUSA. Estos autores se han centrado en la importancia de analizar el papel del Derecho en el proceso de globalización y en las formas como la ley ha sido usada para liberar los mercados y para imponer una cultura jurídica homogénea y hegemónica. El análisis de BERGALLI se ocupa más de la producción estatal del Derecho, mostrando las formas en las cuales el Estado-Nación ha ido perdiendo su centralidad en beneficio de instancias supra estatales, como Naciones Unidas y particularmente la Unión Europea, y en beneficio del Derecho privado producido por y para las grandes corporaciones. DE Sousa (1997 y 1999), por su parte, se ha ocupado de analizar el nuevo sentido de un Derecho posmoderno y las conexiones que se dan entre el Derecho nacional y el Derecho de las comunidades. Estos dos autores presentan la pérdida de centralidad en la producción de significado y constituyen una base para nuestro análisis de los nuevos lugares de producción de significado.

Si nosotros nos referimos a la globalización como el proceso por el cual el capitalismo se ha extendido a todo el mundo, es claro que por su naturaleza el capitalismo es global. Así ha sido mostrado por WALLERSTEIN cuando sostiene que el capitalismo es el primer sistema mundo y en los trabajos de Rosa LuXEMBURGO, MiJAIL BUKHARIN y HILFERDING sobre el imperialismo como una etapa del capitalismo, quienes indican que este posee una tendencia imperial porque necesita ampliar sus mercados para asegurar la plusvalía (BREWER, 1976). De acuerdo con LUXEMBURGO, "el capitalismo es el primer modo de economía con el arma de la propaganda, un modo que tiende a engullir el mundo entero y eliminar las otras economías, sin tolerar rival alguno a su lado. Sin embargo, al mismo tiempo es también el primer modo económico que 
es incapaz de existir por sí mismo, que necesita de otros sistemas como su medio y su suelo. Aunque lucha por ser universal y, de hecho, teniendo en cuenta esta tendencia, debe destruirse, porque es inmanentemente incapaz de llegar a ser una forma universal de producción" (BREwer, Op. cit.: 62). HILFERDING y BUKHARIN, por su parte, mostraron que la etapa del capitalismo financiero conduce al imperialismo, pues las compañías nacionales necesitan del apoyo estatal para tener éxito en su carrera contra otras compañías. El Estado se convierte así en el agente del capital en la arena mundial.

Del mismo modo, si nos referimos a la globalización como el proceso por el cual el Otro ha llegado a ser notado, tiene que decirse que los estudios poscoloniales y la crítica a la modernidad han mostrado que el surgimiento de América permitió al capitalismo ser el primer sistema mundial y a Europa ser el primer centro, dado que América era su primera periferia. Dussel (1995) y QuiJANO (2000) han mostrado que la modernidad no puede ser entendida sin tener en cuenta el rol que el continente americano jugó en el papel de liderazgo de Europa. De acuerdo con Dussel, Europa llegó a ser el centro, después de ser la periferia de China y de India, porque logró incorporar a América bajo su dominio.

Lo que estos autores muestran es que la globalización es algo más que la simple expansión de la economía, pues el capitalismo posee en su estructura una actitud expansiva, por lo que tampoco podemos decir que la globalización como fenómeno económico sea algo completamente nuevo. Tampoco lo es la naturaleza abstracta de la ley y su vocación universal -que es precisamente lo que está bajo la idea de la globalización del Derecho-, pues el proceso de abstracción de la mercancía analizado por MARX en el primer volumen de El Capital tuvo su paralelo en el proceso de abstracción de la ley. La ley nacional definió ciertas categorías abstractas para crear una clase proletaria y de esa forma facilitar el dominio imperial del capitalismo europeo ${ }^{3}$.

Este breve repaso a una mínima parte de la literatura existente acerca de la globalización muestra que esta puede ser analizada desde diversos puntos de vista. Uno es el económico, otro el cultural -la imposición de una cultura local a nivel global o lo que ha sido llamado la McDonaldizacion del mundo-, el que analiza la creación de nuevos sitios de poder, etc.

Pero para los propósitos de este trabajo, me interesa analizar la literatura que se ocupa de la globalización como construcción de nuevas identidades. A través de diferentes instrumentos de producción de sentido, los sujetos son constituidos como parte de un proceso global. La idea de una sociedad civil global y de una ciudadanía global es parte de este proceso de construcción de nuevas identidades globales (HELD, 1998).

3 FitZPATRICK $(2001,1995,1992$ y 1980), Melossi (1992). 
Este proceso ha significado la pérdida de centralidad del Estado-Nación como el lugar de producción de significado. En la Modernidad, el Estado-Nación era el centro de producción de significado y así lo hacía a través de la ley. Sin embargo, se trataba de una centralidad que estaba territorializada y por tanto la ley constituía las identidades nacionales en un territorio determinado. En su análisis acerca de la obra de CARL Schmitt y de Thomas HobBes, John MAcCormick (1994: 619-652) ha mostrado que el soberano se ha convertido en el sujeto con el poder de producir leyes y sentido universal; es decir, el Estado es el productor central de significado en un territorio determinado, lo que hace a través de la ley. A través de esta, los campesinos despojados de la tierra fueron constituidos como trabajadores, ciudadanos y nacionales ${ }^{4}$. Bajo el proceso de globalización, los Estados-Nación han perdido la función de definir el Derecho, su poder de nombrar ha sido transferido de las instituciones nacionales a las instituciones globales de gobierno, como son las Naciones Unidas y la Organización Mundial de Comercio.

Esto se puede observar en la obra de Eve DeRIAN SMITH acerca de la construcción del túnel que une a Francia y a Inglaterra: muestra como la creación del túnel supuso una perturbación en el paisaje inglés y en la identidad de los ingleses. En esta obra ella sostiene que "si la unidad de la nación es equivalente a su ley nacional, como lo sostiene GOODRICH, y así es el caso que 'crear un orden legal es escribir en la ley un sentido de unidad nacional y propósito', ¿cómo puede ser esto entendido en el contexto de la Unión Europea, que encarna a nueva forma de orden legal transnacional y, siguiendo esta lógica, sustancia una nueva forma de nacionalismo omnicomprensivo?". Su respuesta a esta pregunta muestra que la construcción del túnel implicó una transformación de la identidad inglesa, pasando desde lo local a lo global, sin tener en cuenta a lo nacional (SMITH, 1999).

La globalización ha traído consigo la transformación de las identidades. Con la pérdida de lo nacional como sitio central han emergido nuevos lugares para la producción de significado y de identidades. Como lo han mostrado HARDT y NEGRI, esta sociedad disciplinar, caracterizada por un control que carece de lugar, ha sido reemplazada por una sociedad de control que se caracteriza por "una intensificación y generalización de los aparatos normalizadores y de disciplina que internamente animan nuestra prácticas diarias y comunes, pero en contraste con la disciplina, este control se extiende bien fuera de los lugares estructurados de las instituciones sociales a través de redes flexibles y fluctuantes (HARDT y NEGRI, 2001). Este proceso fue definido por Guy Debord (1999) como sociedad del espectáculo, esto es, una sociedad en la que la abstracción de la mercancía ha ido más allá, eliminando a la nación como lugar.

El proceso de globalización ha implicado que la ley nacional haya perdido su poder soberano. Con respecto a la arena internacional, la ley ha sido definida a través del 
uso de las instituciones globales de gobierno. Nuestras concepciones de legal e ilegal no son más el producto de las discusiones de los parlamentos nacionales o de los jueces nacionales: son el resultado de decisiones tomadas en el seno de las Naciones Unidas o de la Organización Mundial de Comercio (TABB, 2001). Pero en lo local, el Estado-Nación ha perdido también su poder de nombrar (BOURDIEU, 1987), porque ahora los individuos, las ONG, los medios de comunicación, etc., han tomado para sí el poder de definir lo correcto y lo incorrecto, incluso en contra de la concepción legal. El Estado-Nación se ha mostrado incapaz de tratar con los problemas globales y locales, y su papel será no más el de un lugar de mediación entre esos dos, como ha venido manifestándose en materia de Derechos Humanos.

\section{LA CUESTIÓN DE LA SOBERANÍA Y EL DERECHO}

La cuestión de la soberanía puede ser entendida como la cuestión de la neutralidad y universalidad. De acuerdo con THOMAs HoBbes (1996), el soberano es una máquina neutral que tiene que estabilizar la sociedad y mediar entre diferentes disputas. Teniendo en cuenta que cada uno de nosotros teme el ataque de todos los hombres, el Estado viene como el único al que necesitamos temer y por tanto como el lugar central de decisión. La guerra civil que HoBBEs vivió fue una guerra religiosa en la que las partes estaban discutiendo el valor de las verdades religiosas. Para HoBBES (Op. cit.: 189), el Estado no puede decidir entre ninguna de ellas; por tanto, la solución que da está basada en la autoridad. De acuerdo con HoBBEs, lo que da valor de verdad a las decisiones del soberano no es el hecho de que sean verdaderas, sino el provienen del poder soberano. Autoritas non veritas facit legem, es la expresión que condensa todo el poder del soberano ${ }^{5}$.

Los individuos crearon al Estado para evitar la guerra civil y centraron su miedo en un hombre artificial. Esta entidad artificial monopolizó la producción de miedo. En KANT, por el contrario, el Estado se convirtió en una máquina de producción de leyes. A través del uso del Derecho, el Estado se convirtió en el lugar central de producción de significado. El Estado monopolizó no solo la producción del Derecho, sino también la producción de la fuerza y de la violencia simbólica, de manera tal que se convirtió en la única institución con el poder de imponer la coerción y sus definiciones del mundo (BENJAMIN, 1991: 23-45).

La soberanía del Estado estaba entonces identificada con su centralidad ${ }^{6}$. Después de la Revolución Francesa, el Estado se convirtió en la unidad que se necesitaba luego de las guerras civiles en Europa. Esta unidad era lograda no solo a través de este

5 "Therefore it is not that Juris prudential or wisedome of subordinate Judges; but the Reason of this our Artificiall man The Common Wealth, and his Command, that maketh law" (HoBBEs, 1996: 187).

6 Melucci (1983), Melossi (2000: 296-320). 
hombre artificial, sino también a través del uso de la ley como la definición de tal unidad. De este modo, el Derecho se convirtió en el instrumento para la creación de la nación, esto es, la unidad de la multitud en un territorio determinado ${ }^{7}$.

Además del discurso de una nación igual a un Estado, existía también el discurso de un Estado igual una ley central, esto es, el único Derecho que se reconocía por parte del Estado era el que el mismo producía. Esta concepción del Derecho apuntaba a la concepción de la ley como el producto del soberano, esto es, el poder central capaz de proteger y por tanto de obligar ${ }^{8}$.

La ley es el producto del soberano, esto es, la autoridad central que gobierna a los miembros de la nación. La nación, como lo ha mostrado PETER FITZPATRICK (Op. cit.), se presenta como la voluntad del pueblo y por ser entendida como un todo da a la ley el carácter de generalidad abstracta, que es su principal característica. La centralización del Estado es producida a través de la protección de la gente de ataques que se producen desde afuera. El Estado europeo fue así construido a través de la soberanía de la nación, y en esta creación desempeñaron un papel muy importante el Derecho y la ley, porque a través de esta el soberano hizo todas las determinaciones con respecto a amigos y a enemigos y especialmente con respecto a la norma y a la excepción ${ }^{9}$. El Leviatán, entonces, era el sitio central de producción de violencia y de significado. En la modernidad, el Estado-Nación puede ser considerado como el locus de producción cultural y simbólica a través de la ley.

\section{LA CONSTRUCCIÓN DEL CRIMINAL EN LA LEY}

Una de las características centrales del Estado-Nación es la centralidad de la ley penal. Desde la Revolución Francesa, se ha entendido como una característica del discurso liberal que la definición de crímenes se centraliza en el Estado, especialmente en el Parlamento nacional. El principio nulla crimen nulla poena sine lege puede ser analizado a través del discurso liberal, señalando que expresa el deseo de la burguesía de retener para sí la definición de los males como verdaderos representantes del

7 KeLSEN (1953), SCHILD (1983).

8 Scheuerman (1994), Schmitt (1985).

9 Para Sснмітт, el corazón de la autoridad del soberano es su poder de determinar la excepción y la normalidad, porque es él quien decide acerca de la restauración de la normalidad a través de la determinación del final del estado de excepción. La excepción muestra dónde reside el poder político. Cfr. Schmitt (1985). Para un análisis de la filosofía de Giorgio Agamben, ver Fitzpatrick (2001). HARDT y NeGRI muestran que en el nuevo orden mundial la excepción determina la aparición de Imperio, esto es, en este Nuevo Orden Mundial, quien decide la excepción llega a ser el verdadero soberano. La relativa y efectiva coincidencia entre lo doméstico y lo internacional es dada por el hecho de que operan en el terreno de la excepcionalidad. La ley doméstica y la ley internacional son definidas por la excepcionalidad (HARDT y NEGRI, 2001: 16). 
pueblo (Feuerbach, 1998). Pero también puede analizarse desde el punto de vista de la protección de la ciudadanía de las definiciones absurdas o de la persecución del Derecho. Esto quiere decir que la definición legal protegería a las personas de acusaciones basadas en crímenes ambiguos, como aquellos de la época nazi ${ }^{10}$. En esta tradición, es la ubicación de la definición del delito la que garantiza la seguridad legal y evita cualquier tipo de abusos. Se hace evidente que el Estado-Nación con todos sus aparatos es el encargado de proteger a las personas de las definiciones arbitrarias.

Sin embargo, después de la Segunda Guerra Mundial, no era el Estado el encargado de defender a las personas de abusos. Esas definiciones de justicia no provenían del Estado, pues era precisamente el Estado el que no era objeto de confianza en estos asuntos. La Declaración de los Derechos Humanos y el proceso de constitucionalismo fueron usados como bases para quitarle al Estado el poder de definición de los delitos y el poder de constitución de las identidades en el territorio nacional ${ }^{11}$.

La criminología europea ha mostrado que el criminal ha sido creado a través del uso de las censuras sociales contenidas en el Derecho ${ }^{12}$. Lo que resulta relevante en este análisis es el hecho de que la ley es el lugar de construcción de las censuras sociales. Como lo ha señalado Colin Sumner (1990), las censuras sociales "han sido parte integral del proceso de formación de los Estados, del mantenimiento del orden y del gobierno". Las censuras sociales son parte de la constitución del Estado y de los individuos. Es la ley el lugar de constitución de los sujetos como criminales. En su análisis de la televisión estadinense, RichARD SPARKS (en SuMnER, 1990) ha mostrado que los programas relacionados con el Derecho han influenciado la percepción pública de la ley. Sin embargo, es necesario señalar que pese al proceso de transformación del Derecho y de sus significados, la ley y el Estado son los lugares centrales de producción de significado.

Este proceso de constitución de significado en el Derecho puede ser analizado a través del positivismo criminológico, esto es, la escuela italiana de criminología que fue ampliamente aplicada en Europa y en Latinoamérica durante el siglo XIX y parte del Xx. Esta escuela concibió al crimen y al criminal como sujetos naturales, pero de hecho lo que ellos estaban haciendo era basarse en el Derecho estatal, que contenía las definiciones y las descripciones del criminal. Después del fracaso de la escuela positiva, diferentes aproximaciones a la cuestión criminal han mostrado que son la ley y el Estado los lugares en donde delito y delincuente son definidos.

La Criminología Crítica, por ejemplo, muestra que el crimen no posee un carácter ontológico, esto es, se trata de una creación del Derecho del Estado (BARATTA, 1983).

10 Ferrajoli (1986: 25-48), Muller (1993), Muñoz Conde (2001).

11 Leary (1990), KLUG (2000).

12 BARATta (1983), Young et al. (1973). 
El Derecho ha constituido no solo a la nación sino a aquellos sujetos que la atacan, es decir, a los criminales (ANDERSON, 1991).

La concepción pluralística de los Derechos y de la ley ha cuestionado esta centralidad de la ley y ha demostrado que el Estado no es el único lugar de producción de significado sino solo uno con un poder hegemónico. Moore, en su análisis del debate acerca de Los versos satánicos, de SALMAN RUSHDIE, muestra que la integración europea conducirá a un creciente multiculturalismo. Lo mismo puede decirse acerca de los Estados Unidos, donde la inmigración ha traído el tercer mundo dentro del primer mundo, haciendo inútil una distinción entre uno y otro. La presencia del tercer mundo en las ciudades de los Estados Unidos conducirá a una creciente pluralidad en la producción de significado y de multiculturalismo en el Derecho (MoORE, 1997). Como Brigham y Santos sostienen, de acuerdo con Moore, "el Estado no tiene un monopolio de la producción del Derecho: más bien, los movimientos sociales han generado al Derecho en la medida en que ha abogado por un cambio. Santos sugiere que el efecto constitutivo del Estado y las 'otras formas generadoras de Derecho', tales como los movimientos populares o comunidades de minorías/inmigrantes, es recíproco, que las relaciones son 'multidireccionales"” (MoORE, Op. cit.).

\section{LA SOCIEDAD ESPECTACULAR}

Las aproximaciones críticas a la modernidad han demostrado que el capitalismo se basa en lo que MARX llamó el fetichismo de la mercancía. Un concepto central en la crítica del capitalismo es el concepto de alienación, esto es, el proceso por el cual los individuos son privados de lo que ellos producen, que no son ya creados para ser consumidos sino para ser intercambiados. De acuerdo con MARX, la primera etapa en ese proceso de alienación es la transición del ser al tener. Este proceso de abstracción alcanza su etapa más alta en la sociedad del espectáculo.

Uno puede equivocarse si piensa que la sociedad del espectáculo se refiere solamente a un análisis de los medios de comunicación. La cuestión en esta sociedad es tratar de entender de qué manera el proletariado es hecho trabajar cuando el uso de la fuerza y la ilusión por una sociedad mejor han desaparecido (DEBORD, Op. cit.: 36). La cuestión puede ser contestada a través del uso del concepto de hegemonía y a través de un análisis de la sociedad del espectáculo.

Por sociedad del espectáculo, DEBORD entiende la más alta etapa en el proceso de abstracción. Como señalé antes, el capitalismo alienó a los seres humanos a partir de hacer más importante el tener que el ser. En la sociedad del espectáculo lo que deviene más importante es el aparecer. "El resultado -de acuerdo con DEBORD- es que la experiencia directa y la determinación de los eventos por los individuos mismos es reemplazada por una contemplación pasiva de las imágenes (que han sido, aun más, escogidas por otra gente) (JAPPE, 1999: 7). En un nivel macro, la sociedad del espec- 
táculo implica la unificación entre el mercado y el Estado. Teniendo en cuenta que el capitalismo es por definición expansionista y el Estado es territorializado, esto significa que una sociedad del espectáculo carece de Estado, esto es, lo global reemplaza a lo nacional. En el nivel micro, el Estado perdió su poder para crear realidades, la realidad es reemplazada ahora por imágenes. "En el proceso, las imágenes terminar convirtiéndose en reales, y las realidades terminan transformadas en imágenes” (ídem: 12).

De acuerdo con DEBORD, los bienes han perdido su valor de uso y son importantes solo por su valor de cambio; esto es, las cosas que compramos las compramos no porque sirvan para algo sino por su valor de intercambio. En este mundo nos convertimos no en productores de significado sino en los receptores pasivos de sgnificados que se producen en otro lugar. En esta sociedad, como en el capitalismo moderno, el individuo tiene valor solo como parte de lo abstracto, por ejemplo, como un ciudadano del Estado, como un individuo de una sociedad liberal (ídem).

El análisis de Debord se basa en la sociedad francesa de los años sesenta, cuando la transformación de las ciudades y los pueblos, la rápida industrialización del país condujo a un estado general de riqueza material y, a la vez, a una pobreza de la vida cotidiana. Esta es la razón por la cual él pregunta qué hacer en este tiempo en el que las condiciones materiales podrían eliminar el trabajo. Él encuentra que una vez que las identidades de los trabajadores han sido creadas a través del proceso de la escuela y de la fábrica, el tiempo de ocio de los trabajadores llega a ser parte del control de la sociedad. Mayo de 1968 fue una protesta en contra de este estado de cosas y fue sorprendente porque el Estado no lo pudo manejar y porque no fue el lugar adecuado para ello. Lo que Mayo del 68 demostró fue la pérdida de centralidad del Estado como lugar de producción de significado (HARDT y NEGRI, Op. cit.: 13).

El trabajo de DeBord es tomado por HARDT y NEGRI para elaborar su argumento acerca de esta época de Imperio. Ellos reconocen que este no es un tiempo de imperialismos, porque el lugar central no es el Estado-Nación, sino un tiempo de Imperio, porque es lo global el lugar de la producción. De acuerdo con NEGRI, DEBORD tenía razón cuando escribió que la sociedad del espectáculo es una sociedad del no-lugar, donde no hay posibilidad de distinguir entre lo público y lo privado, donde no todo es público, sino que todo es privado (ídem: 188). El espectáculo ha llegado a reemplazar al Estado, ahora el miedo de que nos hablaba HoBBES es producido por la sociedad espectacular y no por el Estado (ídem: 323). En la sociedad del espectáculo, el Estado no posee un poder hegemónico, esto es, la producción de la realidad no está centralizada en el Estado o en la ley del Estado-Nación ${ }^{13}$.

13 En GRAMSCI, el principio de hegemonía tiene también una importancia epistemológica, pues "la realización de un nuevo aparato hegemónico, en la medida que crea un nuevo terreno ideológico, determina una reforma de consciencia y de métodos de conocimiento: es un hecho de conocimiento, un hecho filosófico". En su análisis de FouCAult y de Gramsci, Morera señala que la hegemonía es "el poder de determinar aquello que puede ser dicho, pensado, o probado. Si es así, la hegemonía 
En la siguiente parte de este ensayo, me ocuparé del análisis de la producción de significado a nivel local y como se conecta con lo global. A través del análisis de una telenovela colombiana, quiero mostrar cómo los colombianos rechazaron el significado producido en la ley y en su lugar escogieron usar el significado que fue producido en la novela. Mi análisis mostrará que esta pérdida de centralidad es parte del proceso por el cual las producciones culturales son parte de la producción política, descentrando al Estado-Nación como el lugar para constituir la identidad y el significado.

\section{LA CONSTRUCCIÓN DEL SIGNIFICADO EN LO LOCAL}

En 1999, apareció una nueva telenovela en Colombia titulada Yo soy Betty, la fea. El título sugería que se iba a modificar la concepción tradicional acerca de las identidades en las telenovelas colombianas. Además de otras cuestiones, la novela se ocupaba de la contestación del significado producido en la ley del Estado y a cambio ofrecía aquel producido en el programa.

La protagonista era una mujer fea que trabajaba como secretaria en una compañía de modas. Betty, como se llamaba, poseía un elevado nivel de formación profesional, a pesar de la carencia de medios económicos, señalando la posibilidad de que en Colombia miembros de las clases subalternas alcancen niveles educativos y posiciones de poder mediante el respeto a las reglas del juego y a través del sometimiento a los designios de las clases dominantes.

En uno de los episodios se muestra cómo Betty estuvo a punto de recibir un soborno de una de las compañías. Este acto fue discutido por diversos funcionarios públicos en Colombia, entre ellos el entonces presidente PASTRANA y el entonces fiscal ALFONSo GómEz MÉnDEZ, llevando a los escritores del programa a cambiar la trama de la novela. Sin embargo, no ocurrió lo mismo cuando la protagonista creó una compañía ficticia para evitar que los acreedores embargaran a la compañía. Mientras el segundo acto era un delito definido en el Código Penal, el primero no lo era.

La telenovela latinoamericana es el único producto cultural de Latinoamérica que se exporta con sentido comercial. Se trata de un producto hecho para los latinoamericanos y lleno de significado para ellos. Se trata de un producto que es vivido por todas las personas como parte de sus vidas. En la novela se constituyen modelo para la generalidad, lo que hace de ella un aspecto importante de la sociedad del espectáculo. A través de la novela, nuestra percepción de la realidad es modificada, como, por ejemplo, a

ejerce el poder a través de la constitución de un mundo, a través de hacer posible la experiencia de ese mundo y así crear algunos juegos de lenguaje y silenciar otros. La relación entre las narrativas que constituyen nuestro mundo y el poder es bien establecida, o así parece, en las profundidades del pensamiento de GrAMSCI" (MORERA, 2000: 16-46). 
través de presentar una identidad racial diversa a la realmente existente, como es el caso de México y sus personajes blancos, con perjuicio de personajes de origen indígena.

Con el uso de estas producciones culturales, los sujetos se han convertido en ciudadanos y consumidores, esto es, su identidad ha sido modelada sobre la base de la construcción de la identidad hecha en el mercado político y económico. El análisis de Debord nos permite ver cómo los medios de comunicación no son mediadores entre el Estado y la multitud, como lo sostiene BARBERO (1987), sino que ellos son productores de significado y constituyentes de identidades. Como lo ha señalado BAUDRILLARD al hablar del simulacro, la realidad ficticia no es concebida más como ficción, sino que ella misma sustituye a lo real. Teniendo en cuenta que lo que vemos es lo que creemos, la producción del significado en la telenovela contesta la definición del Estado acerca de lo real y con frecuencia lo derrota en ese proceso.

La construcción textual de la telenovela y el juego entre la realidad y la ficción, a través de la presentación de personajes reales en la telenovela, hace que la distinción entre ficción y realidad sea más difícil. Aunque los televidentes puedan distinguir entre realidad y ficción, lo cierto es que el discurso real, al ser mezclado con el ficticio, hace que esa distinción sea más difícil. En el caso de Yo soy Betty, la fea, pese al hecho de que el primer acto no era delictivo, empleados del Estado reaccionaron en contra de esa construcción pidiendo que el discurso ficticio fuera modificado, argumentando que ello modificaría a la propia realidad. En el segundo acto de corrupción, la realidad ficticia impuso su significado sobre los del Estado.

Como muestra el caso de Yo soy Betty, la fea, la soberanía del Estado para constituir el significado es cuestionada por la producción de significado en otros lugares. La sociedad del espectáculo produce este significado fuera del alcance del Estado, pues esto es necesario para desterritorializarlo (BENAVIDES VANEGAS, 2000).

\section{CONCLUSIÓN}

La globalización es el proceso de extensión de la economía capitalista alrededor del mundo. Pero la globalización también es la constitución de significados fuera de los lugares tradicionales de producción en la modernidad. Como se ha mostrado en este ensayo, luego del proceso de globalización, el Estado perdió su capacidad de producción de significado y fue reemplazado por las instituciones de gobierno mundial y por las industrias culturales. El Estado ha perdido su soberanía y esta ha sido reemplazada por el espectáculo.

Como el caso de Yo soy Betty, la fea muestra, el Estado no es más el centro de producción de significado. La realidad ficticia define lo que es legal e ilegal, no la ley del Estado. La democracia no tiene más el Estado como su lugar sino al espectáculo. 


\section{BIBLIOGRAFÍA}

ANDERSON, BENEDICT (1991). Imagined communities. Reflections on the origin and spread of nationalism. Londres/Nueva York: Verso.

Baratta, Alessandro (1983). Criminología Critica y Crítica del Derecho Penal. México: Siglo XXI.

Baratta, Alessandro (1983). "Problemi Sociali e Percezione della Criminalitá", en Dei Delitti e delle pene. Rivista di Studi Sociali, Storici e Giuridice sulla Questione Criminale. Año $1 \mathrm{n} .^{\circ} 1$. (enero-abril, 1983).

MARTín BARBERo, Jesús (1987). De los medios a las mediaciones. Comunicación, cultura y hegemonía. Barcelona: Gustavo Gili.

BECK, UlRICH (1998). Que es la globalización. Madrid: Paidós.

Benavides Vanegas, Farid SAmir (2000). “Corrupción y Derecho Penal”, en Revista de Derecho Penal y Criminología. Bogotá: Universidad Externado de Colombia.

Benjamin, Walter (1991). "Para una crítica de la violencia”, en WALter BENJAmin. Para una crítica de la violencia y otros ensayos. Madrid: Taurus, 23-45.

Bergalli, Roberto (2000). “Globalización y jurisdicción penal. Un desafío para la cultura jurídica moderna”, en FARID SAMIR BenAVides VANEgas, Jaime Córdoba Triviño et al. (eds.), Sentido y Contenidos del Sistema Penal. Bogotá: Ediciones Jurídicas Ibáñez.

Bergalli, Roberto (s.f.). Globalización y control de la ciudad. Fordismo y disciplina - Postfordismo y control punitivo. Disponible en www.ub.es

Bourdieu, Pierre (1987). "The force of law: towards a Sociology of the Juridical Field", en Hastings Law Journal vol. 38 n. ${ }^{\circ}$ 5. University of California, Hatings College of Law.

BREWER, ANTHONY (1990). Marxist theories of Imperialism: a critical survey. London/New York: Routledge.

Brigham, JoHn (1996). The Constitution of Interests. Beyond the politics of rigts. New York: New York University Press,

Debord, Guy (1999). La sociedad del Espectáculo. Barcelona: Pre-Textos. 
De Sousa, Boaventura (1999). Globalización y Derecho. Bogotá: Universidad Nacional de Colombia.

De Sousa, Boaventura (1987). "The Gatt of Law and Democracy: (Mis) trusting the global reform of Courts", en JOHANESS FEEST (ed.). Globalizat and legal cultures. Oñati: Oñati Proceedings.

DusSEl, ENRIQUe (1995). "Beyond Eurocentrism: the World System and the limits of modernity" en The invention of the Americas: Eclipse of the "other" and the myth of modernity. New York: Continuum.

Ferrajoli, Luigi (1986). "El Derecho penal mínimo", en Poder y Control. Revista Hispano Latinoamericana sobre el Control Social. n. ${ }^{\circ}$ 0. Barcelona: PPU, 25-48.

Feuerbach, Ludwig (1998). Derecho Penal Alemán. Buenos Aires: Astrea.

FITZPATRICK, PETER (2001). Bare Sovereignty: Homo Saccer and the instance of Law (dic. 2001. Texto en archivo del autor).

FitzPatrick, Peter (1995). Introducción a Peter FitzPATrick (ed.). Nationalism, racism and the rule of law. Aldershot, Brookfield, Syngapore, Sydney: Darthmond.

FitzPATRICK, PeTER (1992). The mythology of modern law. London, New York: Routledge.

FitzPAtrick, Peter (1980). Law and State in Papua New Guinea. London, New York: Academic Press.

Foucault, Michel (1977). Discipline and Punishment. The birth of the prison. New York: Vintage Books.

Hardt, Michael y Antonio Negri (2001). Empire. Cambridge: Harvard University Press.

Held, DAvid (1998). “Democracy and Globalization”, en DANiEle ArChiBUGi, DAVID Held y MARTIN KoHler (eds.). Re-imagining the political community. Studies in Cosmopolitan Democracy. Stanford: Stanford University Press.

Hobbes, Thomas (1996). Leviathan. Cambridge: Cambridge University Press.

Hunt, Alan (1993). Explorations in Law and Society. Towards a Constitutive Theory of Law. New York: Rutledge.

JAPPE, Anselm (1999). Guy Debord. University of California Press. 
Kelsen, Hans (1953). Teoría Pura del Derecho. Introducción a la Ciencia del Derecho. Bogotá: Editorial Reflexión.

Klug, HeInz (2000). Constituting Democracy: Law, Globalization and South African Political Reconstruction. Cambridge: Cambridge University Press.

Melossi, Dario (1992). El Estado del Control Social. Madrid: Siglo XXI Editores.

Melucci, Alberto (1983). Nazione senza stato. I movimento etnico nazionali in occidente. Torino: Loescher editore.

Lao Montes, Agustin (2001). "Mambo Montage. The Latinizationof New York City", en Lao-Montes, Agustin y Arlene Davila (eds.). Mambo Montage: The latinization of New York. New York: Columbia University Press.

Morera, Esteve (2000). “Gramsci's critical modernity”, en Rethinking Marxism. Vol. 12 n. ${ }^{\circ} 1,16-46$.

LEARY, VIRGINIA (1990). "The effect of western perspectives of International Human Rights”, en Abdullahi Ahmed An-NA'Im y Francis Deng (eds.). Human Rights in Africa. Cross Cultural Perspectives. Washington: The Brookings Institutions.

MAcCormick, John (1994). "Fear, technology and the state: Carl Schmitt, Leo Strauss and the revival of Hobbes in Weimar and National Socialist Germany", en Political Theory Vol. 22 n. $^{\circ} 4$. (November, 1994), 619-652.

Melossi, Dario (2000). "Changing Representations of the Criminal”, en British Journal of Criminology Vol. 40-3, 296-320.

Moore, Kathleen (1997). Legal Studies Forum. Vol. XXI n. 4.

Mudimbe, V.Y. (1988). The Invention of Africa. Gnosis, philosophy, and the order of knowledge. Bloomington: Indiana University Press.

Muller, Ingo (1993). Hitler's Justice. Cambridge ma: Harvard University Press.

Muñoz CONDE, FRANCISCO (2001). Edmundo Mezger y el Derecho penal de su tiempo: estudios sobre el Derecho penal en el nacionalsocialismo. Valencia: Tirant Lo Blanc.

Pavarini, Massimo and Dario Melossi (1977). The Prison and the Factory. New Jersey: Barnes and Noble.

QuiJANO, ANíBAL (2000). "Coloniality of power and Euroentrism in Latin America”, en International Sociology vol. 15 n. ${ }^{\circ} 2 ., 215-232$. 
SAID, EdwARd (1977). Orientalism. New York: Pantheon Books.

Scheuerman, WiLliam (1994). Between the norm and the exception: the Frankfurt School and the Rule of Law. Cambridge, MA: MIT.

Schild, Wolfgang (1983). Las Teorías Puras del Derecho. Bogotá: Monografías Jurídicas Temis n. ${ }^{\circ} 32$.

Schmitt, CARL (1985). Political Theology. Four chapters on the concept of sovereignty. Cambridge, MA: MIT.

Sierra, María Teresa (1995). "Indian Rights and Customary Law in Mexico: a study of the Nahuas in the Sierra de Puebla", en Law and Society Review Vol. 29 n. $2,227-254$.

Smith, Eve Derian (1999). Bridging Divides. The Channel Tunnel and English Legal Identity in the New Europe. University of California Press.

Sumner, Colin (1990). Introduction to Censure, politics and Criminal Justice. Philadelphia: Open University Press/Milto Keynes.

TABв, William (2001). The amoral elephant: Globalization and the struggle for social justice in the Twenty First Century. New York: Monthly Review Press.

Thompson, E. P. (1975). Whigs and Hunters. The origins of the Black Act. New York: Pantheon Books.

Vattimo, Gianni (1991). La sociedad transparente. Madrid: Anthropos.

WALLERSTEIN, IMMANUEL (1976). Capitalist agriculture and the origins of the European world economy in the sixteenth century. New York: Academic Press.

Young, Jock et al. (1973). The New Criminology: for a social theory of deviance. London: Routledge and Kegan Paul. 
